\title{
Hexavalent Chromium Adsorption from Aqueous Solution Using Orange Peel Modified with Calcium Chloride: Equilibrium and Kinetics Study
}

\author{
C. Tejada-Tovar', A. Herrera-Barros ${ }^{2}$, A. Villabona-Ortíz', \\ Á. González-Delgado ${ }^{2 *}$, and J. Núñez-Zarur ${ }^{1}$ \\ 'Department of Chemical Engineering, Process Design and Biomass Utilization Research Group (IDAB), \\ University of Cartagena, Cartagena, Bolívar, Colombia; ctejadat@unicartagena.edu.co, \\ avillabonao@unicartagena.edu.co,jnuñezz@unicartagena.edu.co \\ 2Department of Chemical Engineering, Nanomaterials and Computer Aided Process Engineering \\ Research Group (NIPAC), University of Cartagena, Cartagena, Bolívar, Colombia; \\ aherrerab2@unicartagena.edu.co, agonzalezd1@unicartagena.edu.co,
}

\begin{abstract}
Background: Adsorption technology using residual biomass has gained attention as a low-cost alternative for removing $\mathrm{Cr}$ (VI) ions from aqueous solutions. Objectives: This work attempts to study the effect of orange peel modification with $\mathrm{CaCl}_{2}$ on $\mathrm{Cr}(\mathrm{VI})$ ions uptake in batch and continuous system. In addition, $\mathrm{pH}$ and particle size were evaluated to determine suitable values for carrying out adsorption process. Methods/Analysis: $\mathrm{OP}-\mathrm{CaCl}_{2}$ and $\mathrm{OP}$ biosorbents were characterized by FT-IR analysis in order to identify their functional groups. The $\mathrm{pH}$ of heavy metal ions solutions was adjusted to 2, 3, 4 and 6 and adsorbent particle size was varied in $0.355,0.5$ and $1 \mathrm{~mm}$. Experimental data for batch experiments were used to calculate adsorption isotherms and kinetic. The results of adsorption on packed-bed columns were fitted to dynamic models. Desorption process was also studied to determine reusability of biomass. Findings: It was found that hydroxyl, carboxyl and aliphatic groups are the main contributors to adsorption process. The highest removal yield (86\%) was achieved at $\mathrm{pH}$ of 2 and particle size of $0.355 \mathrm{~mm}$. The chemical reticulation with $\mathrm{CaCl}_{2}$ did not improve adsorption capacity of orange peel biosorbent. Kinetic and isotherm models that best fit experimental data were Elovich's and Freundlich's, respectively. Regarding continuous systems, data obeyed Yoon-Nelson and Dose-response models with $\mathrm{R}^{2}=0.99$. Desorption study with $\mathrm{HCl}$ reported a removal yield of $43.7 \%$ for second cycle of biosorbent use. Novelty/Improvement: These results suggested that orange peel is a suitable biosorbent alternative for removing $\mathrm{Cr}$ (VI).
\end{abstract}

Keywords: Adsorption Kinetics, Biosorption, Chromium Hexavalent, Isotherms, Removal

\section{Introduction}

Heavy metals in water sources have been a major issue due to its toxicological effect on environment and health. These pollutants get absorbed and accumulated in human body, causing serious health diseases such as cancer, damaging of nervous system, organ damage and even death ${ }^{1,2}$. They do not degrade physical o chemically and can bioconcentrate on moving up in the food chain ${ }^{3,4}$. Chromium is considered one of the 14 most noxious heavy metals and it is widely used in electroplating, leather tanning, metal finishing and chromate preparation ${ }^{5,6}$. The maximum concentration of chromium allowed in drinking water is 0.05 $\mathrm{mg} / \mathrm{L}^{7}$. Hence, the removal and recovery of chromium is important for environmental protection, human health and economic reasons ${ }^{8}$. Chemical procedures as reverse osmosis, coagulation, chemical precipitation, electro dialysis and ultra-filtration are widely employed to wastewater

${ }^{*}$ Author for correspondence 
treatment ${ }^{9}$. Among these methods, adsorption has gained importance in the purification of all types of waters as it is environment friendly and a low cost technology ${ }^{10}$. Several materials have been tested to adsorb heavy metal ions from water solutions, however, agricultural waste products represent unused and widely available resource with great potential to be used as adsorbents ${ }^{11}$. Different biosorbents have been obtained from residual biomass to adsorb $\mathrm{Cr}$ (VI) in batch and continuous system as: pecan nut husks ${ }^{12}$, olive stone ${ }^{13}$, mustard oil cake $e^{14}$, activated carbon from Swietenia mahogani fruit shells ${ }^{15}$, rice straw ${ }^{16}$, $\mathrm{ZnCl}_{2}$ impregnated activated carbon derived by Jatropha curcas seed hull ${ }^{17}$, among others. Orange peels are one of the valuable waste materials discarded from juice industry with great potential to remove pollutants from wastewater ${ }^{18}$. Therefore, this work attempts to study adsorption equilibrium and kinetic of $\mathrm{Cr}$ (VI) ions using orange peel (Citrus sinensis) biosorbent and evaluate the effect of its chemical modification with $\mathrm{CaCl}_{2}$ on removal yield.

\section{Material and Methods}

\subsection{Materials}

Potassium dichromate, calcium chloride, sodium hydroxide and hydrogen chloride were purchased from Merck in analytic grade. Orange peel (Citrus sinensis) biomass was obtained from a local fruit market.

\subsection{Biosorbent Preparation}

\subsubsection{Orange Peels (OP)}

Orange peels were washed with enough water to remove impurities and soluble compounds such as surface tannins, reducing sugar resin and pigments that can affect adsorption process. They were dried to $90^{\circ} \mathrm{C}$ during 24 hours and milled to $1,0.5$ and $0.355 \mathrm{~mm}$ particle size.

\subsubsection{Modification with $\mathrm{CaCl}_{2}$}

The content of pectin in orange peels can be reticulated using different chemicals as $\mathrm{CaCl}_{2}$ in order to improve its adsorption capacity ${ }^{19}$. In this study, $20 \mathrm{~g}$ of OP dried biomass was kept in contact with $500 \mathrm{~mL}$ of $0.2 \mathrm{M} \mathrm{CaCl}_{2}$ solution during 24 hours. Afterwards, the sample was washed with distillated water and filtered to remove excess of chlorine and calcium. Finally, $\mathrm{OP}-\mathrm{CaCl}_{2}$ was dried in an oven during 3 hours $^{20}$.

\subsection{Characterization of Biosorbents}

The OP- $\mathrm{CaCl}_{2}$ biosorbentwas characterized by Fourier Transform Infrared Spectroscopy to identify chemical groups in biomaterial molecules. The FT-IR analysis of samples was recorded on Nicolet 6700 spectrophotometer in the range between $4000-500 \mathrm{~cm}^{-1}$.

\subsection{Batch Adsorption Experiments}

The experiments of adsorption on batch mode were performed in a shaker at room temperature $\left(25^{\circ} \mathrm{C}\right)$ during 2 hours. Stock solution of chromium (100 ppm) was prepared by dissolving potassium dichromate $\left(\mathrm{K}_{2} \mathrm{Cr}_{2} \mathrm{O}_{7}\right)$ in deionized water. Then, $100 \mathrm{~mL}$ of this solution was mixed with $0.5 \mathrm{~g}$ of biosorbent inside a flask placed on a stirrer plate. The effect of $\mathrm{pH}$ on adsorption process was evaluated by adjusting $\mathrm{pH}$ to 2, 3, 4 and 6 with $0.5 \mathrm{~N}$ $\mathrm{HCl}$ and $\mathrm{NaOH}$ solutions. The residual heavy metal ions concentration was measured using diphenylcarbazide acid solution using anUV/Vis Shimdzu UV 1700 spectrometer. The concentration of $\mathrm{Cr}$ (VI) ions retained by biomass was calculated according to Equation 1, where $\mathrm{C}_{\mathrm{o}}(\mathrm{mmol} / \mathrm{L})$ is the initial $\mathrm{Cr}(\mathrm{VI})$ concentration in the solution, $\mathrm{C}_{\mathrm{f}}(\mathrm{mmol} / \mathrm{L})$ is the $\mathrm{Cr}(\mathrm{VI})$ concentration in the solution after adsorption, $\mathrm{V}_{\mathrm{o}}(\mathrm{L})$ is the initial volume of $\mathrm{Cr}(\mathrm{VI})$ solution, $\mathrm{V}_{\mathrm{f}}$ is the final volume of $\mathrm{Cr}(\mathrm{VI})$ solution and $\mathrm{m}$ is the dried mass of used $\mathrm{OP}-\mathrm{CaCl}_{2}$ biosorbent.

$$
q=\frac{C_{O} V_{O}-C_{f} V_{f}}{m}
$$

\subsection{Kinetic Studies and Adsorption} Isotherms

The adsorption kinetic of lignocellulosic materials was studied in order to determine the required contact time to attain adsorption equilibrium. In brief, $0.5 \mathrm{~g}$ of $\mathrm{OP}$ and OP- $\mathrm{CaCl}_{2}$ biosorbent were shaken with $100 \mathrm{~mL}$ of 100 ppm $\mathrm{Cr}(\mathrm{VI})$ ions solution on a reciprocating shaker at $150 \mathrm{rpm}$ at a constant temperature of $25^{\circ} \mathrm{C}$. Suitable $\mathrm{pH}$ and particle size operating conditions were considered in these experiments. Aliquots of $5 \mathrm{~mL}$ were taken periodically between 10-330 minutes. Pseudo-first order, pseudosecond order, Elovichand intra-particle diffusion models were selected to explain the adsorption process of $\mathrm{Cr}$ (VI) and $\mathrm{OP}-\mathrm{CaCl}_{2}$. Experimental data for fitting to isotherms model were taken under same conditions as described above and using different initial Cr (VI) concentration 
$(25,50,75$ and $100 \mathrm{ppm})$. Empirical isotherms (Langmuir and Freundlich) were selected to evaluate the adsorption equilibrium of $\mathrm{OP}-\mathrm{CaCl}_{2}-\mathrm{Cr}(\mathrm{VI})$.

\subsection{Bioadsorption Experiments in Continuous Systems}

The adsorption experiments in continuous system were carried out on lab-scale equipment based on 4 packedbed columns with diameter of $3.5 \mathrm{~cm}$ and height of 18.5 $\mathrm{cm}$. The system required a pump and 9 valves to distribute $0.1 \mathrm{~mL} / \mathrm{s}$ of $\mathrm{Cr}$ (VI) solution throughout these columns. Aliquots of $5 \mathrm{~mL}$ were taken after 270 minutes of contact time in order to analysis the behaviour of biomass to remove heavy metal ions and the time in which the packed-bed achieved breakthrough concentration (5\% of initial concentration). The experimental data were fitted to Yoon-Nelson, Thomas, Dose-response and BohartAdams models that are frequently used in literature.

\subsection{Desorption Studies}

Desorption of Cr (VI) ions was performed to study the reusability of biomass in adsorption cycles. This process was carried out by adding $10 \mathrm{~g}$ used $\mathrm{OP}$ to $25 \mathrm{~mL}$ of $0.2 \mathrm{M}$ $\mathrm{HCl}$ in a recipient placed on a shaker at $150 \mathrm{rpm}$ during 30 minutes, followed by a washing with abundant distillated water to remove acid traces.

\section{Results and Discussion}

\subsection{Characterization of Biosorbent}

In order to determine chemical structure of biosorbent materials and their functional groups that can have affinity with $\mathrm{Cr}(\mathrm{VI})$ ions, $\mathrm{OP}$ and $\mathrm{OP}-\mathrm{CaCl}_{2}$ biosorbents were characterized by FT-IR analysis. Figure 1 shows infrared spectra of $\mathrm{OP}$ and $\mathrm{OP}-\mathrm{CaCl}_{2}$ before and after adsorption process. The peak at $3300 \mathrm{~cm}^{-1}$ is assigned to hydroxyl group $(\mathrm{OH})$ stretching vibrations, which are reported in $3400-3000 \mathrm{~cm}^{-1} \mathrm{range}^{21}$. In addition, it was identified peaks at $1732 \mathrm{~cm}^{-1}, 1615-1684 \mathrm{~cm}^{-1}, 1558 \mathrm{~cm}^{-1}$ and $1235 \mathrm{~cm}^{-1}$ attributed to $\mathrm{C}=\mathrm{O}, \mathrm{C}=\mathrm{C}, \mathrm{C}-\mathrm{H}$ and $\mathrm{C}-\mathrm{O}$ stretching vibrations, respectively ${ }^{22}$. These functional groups are characteristic of carboxyl, aromatic rings, hydroxyl, methyl and methoxy present in main components of lignocellulosic biomass as pectin, hemicellulose and lignin ${ }^{23}$.

\subsection{Batch Adsorption Experiments}

\subsubsection{Effect of Solution $\mathrm{pH}$ and Biosorbent} Particle Size

The $\mathrm{pH}$ of the solution is an important parameter for carrying out adsorption because it modifies charge of biosorbent surface, ionization degree and speciation of sorbate species. As is well known, adsorption process

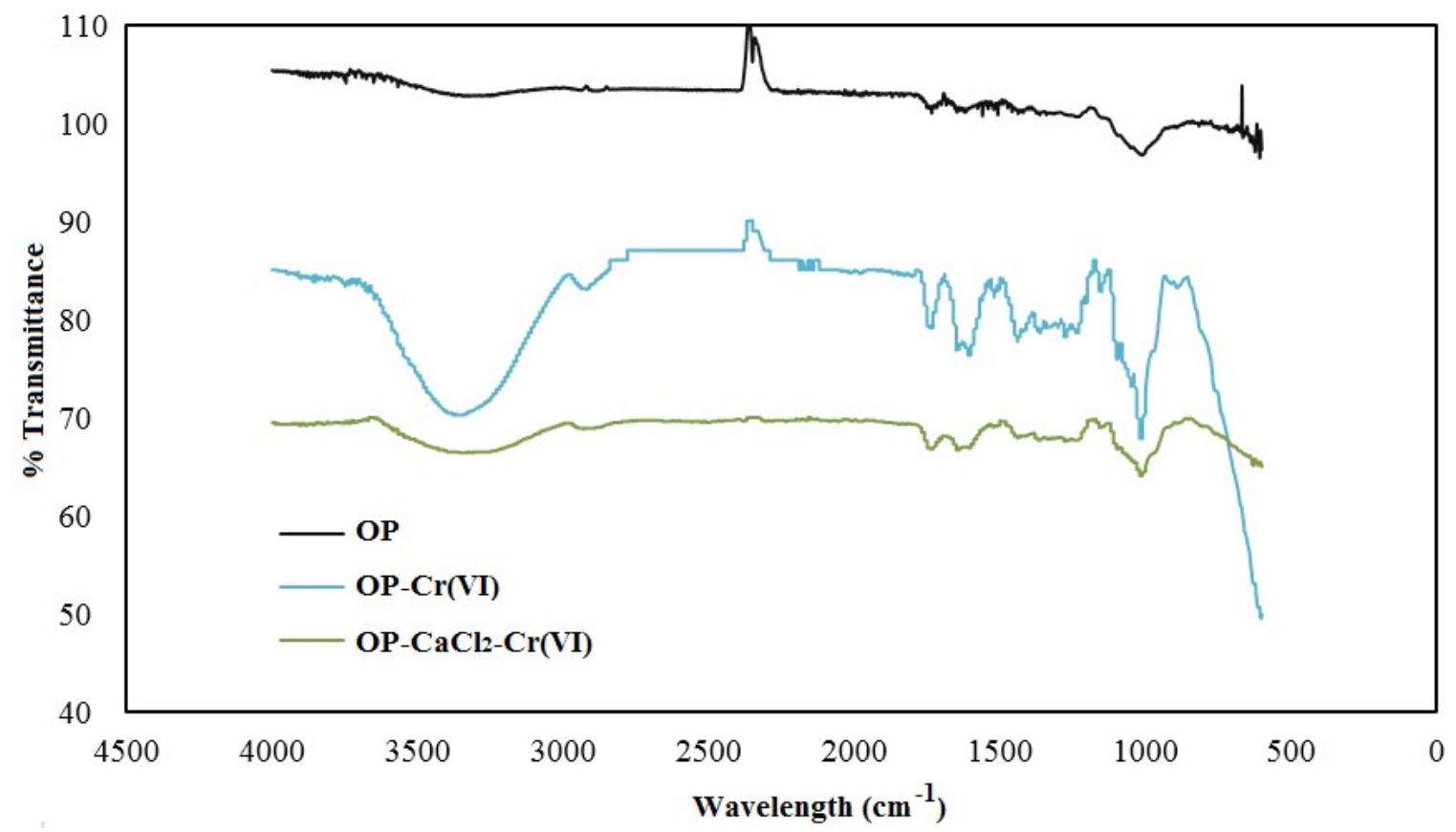

Figure 1. FT-IR spectra of $\mathrm{OP}$ and $\mathrm{OP}-\mathrm{CaCl}_{2}$ biosorbents before and after $\mathrm{Cr}$ (VI) adsorption. 
takes place on pores surface. The amount of solute that can be adsorbed is directly proportional to volume, hence, to surface area that is significantly affected by particle size of biosorbents. The effect of $\mathrm{pH}$ and particle size on removal yield of $\mathrm{Cr}(\mathrm{VI})$ ions using $\mathrm{OP}$ and $\mathrm{OP}-\mathrm{CaCl}_{2}$ biosorbents are shown in Figure 2.

The removal yield of heavy metal ions in aqueous solution using $\mathrm{OP}$ and $\mathrm{OP}-\mathrm{CaCl}_{2}$ biosorbents was calculated by eq. (2).

$$
\text { Removal yield }(\%)=\frac{\left(C_{o}-C_{e}\right.}{C_{o}} 100 \%
$$

It was found that adsorption capacity of orange peel biomass is dramatically affected by $\mathrm{pH}$ exhibiting an increase in removal yield when $\mathrm{pH}$ decreases as is shown in Figure 2a). According to the highest adsorption removal yield $(30.6 \%)$, it was selected $\mathrm{pH}=2$ as suitable value for carrying out further experiments. The experimental results can

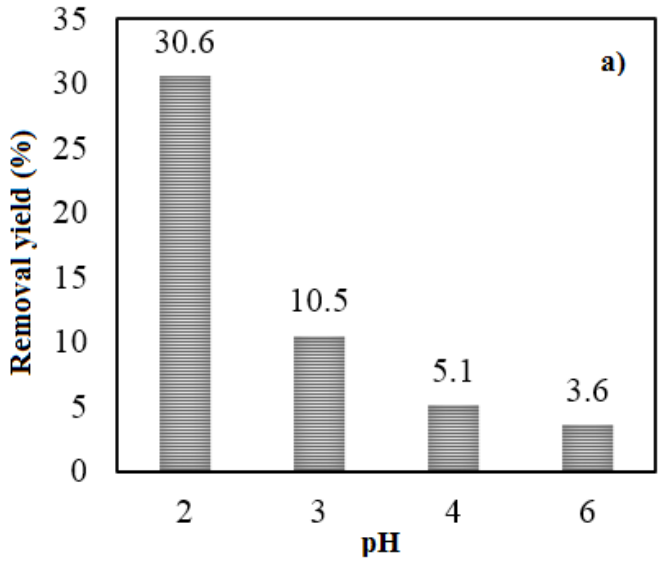

be explained by protonation of biosorbent surface due to high amount of $\mathrm{H}^{+}$ions increasing attraction between these and chromium anions $\mathrm{s}^{24,25}$. In range of $\mathrm{pH}=2-6$, the predominant form is $\mathrm{Cr}_{2} \mathrm{O}_{7}{ }^{2-}$ and $\mathrm{HCrO}_{4}$ ions ${ }^{26}$; for higher $\mathrm{pH}$ chromium is present as $\mathrm{CrO}_{4}^{2-}$ ions and its affinity is relatively low in comparison to $\mathrm{Cr}_{2} \mathrm{O}_{7}^{2-}$ and $\mathrm{HCrO}_{4}$. Figure $2 \mathrm{~b}$ ) shows that removal yield of $\mathrm{Cr}$ (VI) increased when particle size was reduced, which is attributed to high surface area of small size particles and porosity of biomaterials ${ }^{27}$. The highest value for removal yield was achieved using $0.355 \mathrm{~mm}$ particle size, similar results to those reported by ${ }^{28}$.

\subsubsection{Kinetic Studies and Adsorption Isotherms}

The kinetic study was performed to stablish the adsorption mechanism of $\mathrm{Cr}$ (VI) on biosorbents from orange peels (OP and $\mathrm{OP}-\mathrm{CaCl}_{2}$ ) fitting experimental data to kinetic models of pseudo-first order, pseudo-second

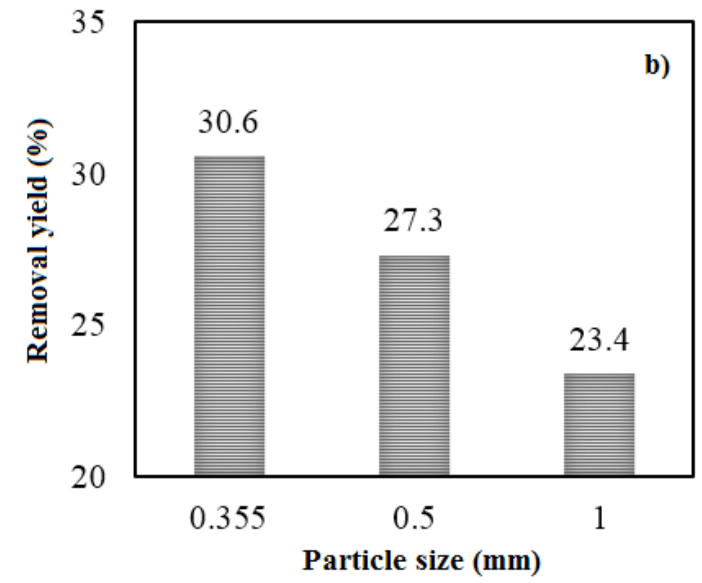

Figure 2. Effect of: a) $\mathrm{pH}$ and b) particle size on removal yield of $\mathrm{Cr}(\mathrm{VI})$ ions.

Table 1. Kinetic models of adsorption

\begin{tabular}{|l|l|l|}
\hline Kinetic model & Equation & Parameters \\
\hline Pseudo-1st-order & $q_{t}=q_{e, 1}\left(1-e^{-k t}\right)$ & $\begin{array}{l}\boldsymbol{q}_{\mathrm{e}} \text { Adsorption capacity at equilibrium }(\mathrm{mmol} / \mathrm{g}) \\
\boldsymbol{k}_{\mathrm{r}} \text {, pseudo-1st-order constant }\left(\mathrm{min}^{-1}\right)\end{array}$ \\
\hline Pseudo-2nd-order & $q_{t}=\frac{t}{\left(\frac{1}{\left(k_{2} q_{e, 2}^{2}\right)}\right)+\left(\frac{t}{q_{e, 2}}\right)}$ & $\begin{array}{l}\boldsymbol{k}_{2} \text { pseudo-2nd-order constant }(\mathrm{g} / \mathrm{mmol} \text { min }) \\
\boldsymbol{q}_{\mathrm{e}} \text { Adsorption capacity at equilibrium }(\mathrm{mmol} / \mathrm{g})\end{array}$ \\
\hline Elovich equation & $q_{t}=\frac{1}{\beta} \ln (\alpha \beta)+\frac{1}{\beta} \ln t$ & $\begin{array}{l}\alpha, \text { Elovich constant }(\mathrm{mmol} / \mathrm{g} \mathrm{min}) \\
\beta, \text { Elovich exponent }(\mathrm{g} / \mathrm{mmol})\end{array}$ \\
\hline Intra-particle diffusion & $q_{t}=k \sqrt{t}$ & $\boldsymbol{k}$, diffusion constant \\
\hline
\end{tabular}

Source: $\operatorname{In}^{34}{ }^{35}$ 
order, Elovich and intra-particle diffusion. The mathematical expression for these models are presented in Table 1.The adsorption process involves: mass transfer of ions from solution to biosorbent surface, $\mathrm{Cr}$ (VI) ions adsorption in available sites of biosorbent and intern diffusion of solute onto biosorbent ${ }^{29}$. Hence, adsorption capacity-time curves was plotted and fitted to models using non-lineal regression by minimization of sum of squares (SS).

Figure 3 shows kinetic models curves and experimental data for OP and $\mathrm{OP}-\mathrm{CaCl}_{2}$ biomaterials, in which $\mathrm{Cr}$ (VI) ions was rapidly removed from aqueous solution during first minutes. It was observed that Elovich model best fits batch adsorption results with sum of squares of 4.88 and 2.47. This suggested that hexavalent chromium ions uptake mainly obeys chemisorption with second order heterogenic reaction mechanism. However, batch adsorption results exhibited a reduction in adsorption potential of both biomasses. The highest removal yields of $43.7 \%$ and $21.2 \%$ were achieved for OP and $\mathrm{OP}-\mathrm{CaCl}_{2}$ biosorbents, respectively, which indicated that $\mathrm{CaCl}_{2}$ agent did not interact or react with biomass; hence, OP only suffered a physical modification by covering its surface instead of chemical modification. This phenomenon can occur due to not complete carboxylation reaction, which is responsible of incorporating additional functional groups to the biomaterial ${ }^{30}$. It is suggested other modifications for further studies that can include carboxyl and hydroxyl groups to biomaterials chemical structure.

Table 2 summarized parameter models used in this work. According to Elovich model, initial adsorption rate (a) was higher for $\mathrm{OP}-\mathrm{CaCl}_{2}$ than for OP indicating the rapid removal of $\mathrm{Cr}$ (VI) ions in aqueous solution using modified biomass, however OP biosorbent exhibited higher surface to uptake heavy metal ions.

Table 2. Parameters of main adsorption kinetic models for $\mathrm{Cr}(\mathrm{VI})$ uptake using OP and OP-CaCl 2 biosorbents

\begin{tabular}{|l|c|c|c|}
\hline Kinetic model & Parameter & OP & OP-CaCl \\
\hline \multirow{3}{*}{ Pseudo-first order } & $q_{e, 1}$ & 7.488 & 4.022 \\
\cline { 2 - 4 } & $k_{1}$ & 0.028 & 0.079 \\
\cline { 2 - 4 } & $\mathrm{SS}$ & 11.761 & 6.285 \\
\hline \multirow{3}{*}{ Pseudo-second order } & $k_{2}$ & 0.0037 & 0.029 \\
\cline { 2 - 4 } & $q_{e, 2}$ & 8.663 & 4.267 \\
\cline { 2 - 4 } & $\mathrm{SS}$ & 1.191 & 3.56 \\
\hline \multirow{3}{*}{ Elovich equation } & $\beta$ & 0.592 & 2.062 \\
\cline { 2 - 4 } & $\alpha$ & 0.699 & 11.58 \\
\cline { 2 - 4 } & $\mathrm{SS}$ & 4.88 & 2.47 \\
\hline \multirow{3}{*}{ Intra-particle diffusion } & $k$ & 0.526 & 0.292 \\
\cline { 2 - 4 } & $\mathrm{SS}$ & 13.33 & 10.198 \\
\hline
\end{tabular}

The experimental equilibrium of solute in solid-liquid phase was modeled by Langmuir and Freundlich isotherm. These models describe the energy distribution of active sites that can be homogeneous or heterogeneous. In addition, they suggested monolayer or multilayer adsorption and interactions between adsorbed molecules ${ }^{31}$. Langmuir and Freundlich isotherms are expressed by Equations (3) and (4), respectively.



Figure 3. $\mathrm{Cr}(\mathrm{VI})$ adsorption experimental data fitting to kinetic models for: a) $\mathrm{OP}$ and b) $\mathrm{OP}_{-} \mathrm{CaCl}_{2}$ biosorbents. 


$$
\begin{gathered}
\frac{C_{e}}{q_{e}}=\frac{1}{K_{L} q_{m}}+\frac{C_{e}}{q_{m}} \\
\ln q_{e}=\ln K_{F}+\left(\frac{1}{n}\right) \ln C_{e}
\end{gathered}
$$

Where $q_{m}$ is the maximum adsorption capacity $(\mathrm{mmol} / \mathrm{g})$, $\mathrm{C}_{e}$ is the equilibrium concentration of $\mathrm{Cr}(\mathrm{V})$ ions (mmol/l), $q_{e}$ is the amount of $\mathrm{Cr}(\mathrm{V})$ ions adsorbed per unit of adsorbent at equilibrium ( $\mathrm{mmol} / \mathrm{g}$ ), $K_{L}$ is Langmuir constant $(\mathrm{L} / \mathrm{mmol}), K_{F}$ is Freundlich constant and $n$ is a heterogeneity factor.

The Cr (VI) adsorption process using both OP and $\mathrm{OP}-\mathrm{CaCl}_{2}$ biosorbents obeyed Freundlich isotherm model as is shown in Figure 4, which suggested a heterogeneous surface of biomass, multilayer formation andnon-uniform distribution of heat of adsorption over the surface ${ }^{24,32}$.

The Langmuir and Freundlich mathematical model parameters are presented in Table 3 . The heterogeneity factor $(1 / \mathrm{n})$ determines adsorption favourability and depends on temperature and adsorbate/adsorbent properties. It has been reported that values of $n>1$ represented a chemical adsorption process and favorable adsorption ${ }^{24}$. In this study, both $\mathrm{OP}$ and $\mathrm{OP}-\mathrm{CaCl}_{2}$ biosorbents exhibited values of $\mathrm{n}$ equal to 1.8 and 10.2 , respectively, suggesting that these materials experiment chemisorption. However, the maximum adsorption capacity parameter of Langmuir model was higher for OP biosorbent (12.29 $\mathrm{mg} / \mathrm{g}$ ) than $\mathrm{OP}-\mathrm{CaCl}_{2}$ biosorbent $(4.95 \mathrm{mg} / \mathrm{g})$. Therefore, modification with $\mathrm{CaCl}_{2}$ did not improve orange peel biomass performance for removing $\mathrm{Cr}$ (VI) from aqueous solution.

Table 3. Parameters of Langmuir and Freundlich models for adsorption of $\mathrm{Cr}$ (VI) onto OP and $\mathrm{OP}-\mathrm{CaCl}_{2}$ biosorbents

\begin{tabular}{|l|l|c|c|}
\hline \multicolumn{2}{|l|}{ Parameters } & OP & OP-CaCl \\
\hline \multirow{4}{*}{ Langmuir } & $q_{m}(\mathrm{mg} / \mathrm{g})$ & 12.29 & 4.95 \\
\cline { 2 - 4 } & $K_{L}(\mathrm{~L} / \mathrm{mg})$ & 0.029 & 0.33 \\
\cline { 2 - 4 } & $\mathrm{SS}$ & 30.62 & 30.61 \\
\hline \multirow{4}{*}{ Freundlich } & $(\mathrm{mg} / \mathrm{g})$ & 0.833 & 3.12 \\
\cline { 2 - 4 } & $1 / n$ & 0.555 & 0.098 \\
\cline { 2 - 4 } & $\mathrm{SS}$ & 0.6025 & 0.6023 \\
\hline
\end{tabular}

\subsection{Adsorption Experiments in Continuous System}

The batch adsorption experiments provided suitable operating conditions of solution $\mathrm{pH}$ and biosorbent particle size for carrying out dynamic adsorption process in packed-bed columns. In order to design an adsorption column, it is necessary to predict the concentration-like profile and adsorption capacity of biosorbent for the selected adsorbate. Figure 5 shows breakthrough curve for sorption process in fixed bed using OP biosorbent. It
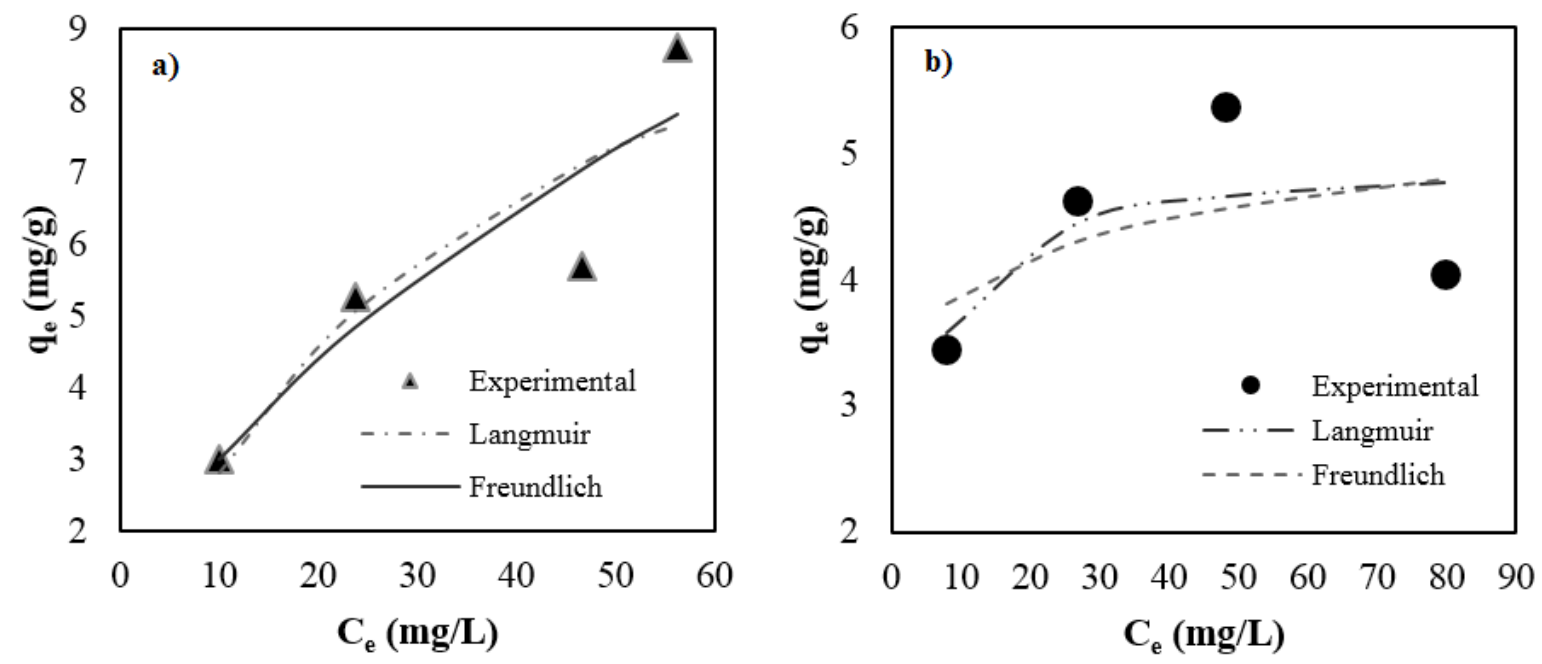

Figure 4. Experimental data of adsorption equilibrium fitting to Freundlich and Langmuir model using: a) $\mathrm{OP}$ and b) $\mathrm{OP}-\mathrm{CaCl}_{2}$. 




Figure 5. Models for the adsorption process of $\mathrm{Cr}$ (VI) in continuous systems using OP biosorbent.

was observed that break through time of OP was $120 \mathrm{~min}$ and adsorption capacity at this point $\left(\mathrm{Q}_{\text {break }}\right)$ was calculated by Equation 5, where the time is which outlet concentration is $5 \%$ of initial concentration, is flow rate in $\mathrm{L} /$ min and is biomass amount.

$$
\operatorname{Qbreak}\left(\frac{m g}{g}\right)=\frac{Q_{v} \tau_{5 \%} C_{o}}{m}
$$

It was found that adsorption capacity at breakthrough time was $10.28 \mathrm{mg} / \mathrm{g}$. In addition, the fitting of experimental data to different dynamic adsorption models is shown in Figure 5. Both Yoon-Nelson and Dose-response models best fitted the Cr (VI) uptake using OP biosorbent packed bed. Parameters of Yoon-Nelson, Thomas, Dose-response and Bohart-Adams models are presented in Table 4.

\subsection{Desorption Studies}

Desorption in batch system offers information about reusability of adsorbent reducing operational cost when it is applied to industrial scale. The orange peels biosorbent was subjected to three adsorption cycles after being desorbed by $0.2 \mathrm{M} \mathrm{HCl}$. It was found that biomass after acid treatment can be reused for further adsorption process as shown Figure 6 . The capacity for removing $\mathrm{Cr}(\mathrm{VI})$ ions decreased approximately to $20 \%$ and $10 \%$ during first and third cycle, suggesting that this biomass can be used several times in cycles without affecting its properties. On
Table 4. Experimental data fitting to models of adsorption in continuous system

\begin{tabular}{|c|c|c|}
\hline Model & Parameter & Value \\
\hline \multirow{4}{*}{ Thomas (Th) } & $k_{t h}\left(\mathrm{~mL} \mathrm{mg}{ }^{-1} \mathrm{~min}^{-1}\right)$ & 0.04 \\
\hline & $q_{o}\left(\mathrm{mg} \mathrm{g}^{-1}\right)$ & $1.11 \times 10^{-14}$ \\
\hline & $R^{2}$ & 0.79 \\
\hline & SS & 0.088 \\
\hline \multirow{4}{*}{$\begin{array}{l}\text { Adams-Bohart } \\
\text { (AB) }\end{array}$} & $k_{A B}\left(\mathrm{~L} \mathrm{mg}^{-1} \mathrm{~min}^{-1}\right)$ & $4.49 \times 10^{-6}$ \\
\hline & $N_{o}\left(\mathrm{mg} \mathrm{L}^{-1}\right)$ & 7050.35 \\
\hline & $R^{2}$ & 0.0189 \\
\hline & SS & 0.978 \\
\hline \multirow{4}{*}{ Yoon-Nelson (YN) } & $k_{Y N}\left(\min ^{-1}\right)$ & 0.88 \\
\hline & $\tau(\min )$ & 8.80 \\
\hline & $R^{2}$ & 0.99 \\
\hline & SS & 0.001 \\
\hline \multirow{4}{*}{$\begin{array}{l}\text { Dose-response } \\
\text { (DR) }\end{array}$} & $\alpha$ & 18.989 \\
\hline & $q_{O}\left(\mathrm{mg} \mathrm{g}^{-1}\right)$ & 6.015 \\
\hline & $R^{2}$ & 0.993 \\
\hline & SS & 0.1016 \\
\hline
\end{tabular}

the other hand, the amount of heavy metal ions desorbed was 20 and $43.7 \%$ after 120 and $270 \mathrm{~min}$, respectively, hence, it is recommended to evaluate other eluents in order to achieve higher desorption yield ${ }^{33}$. 


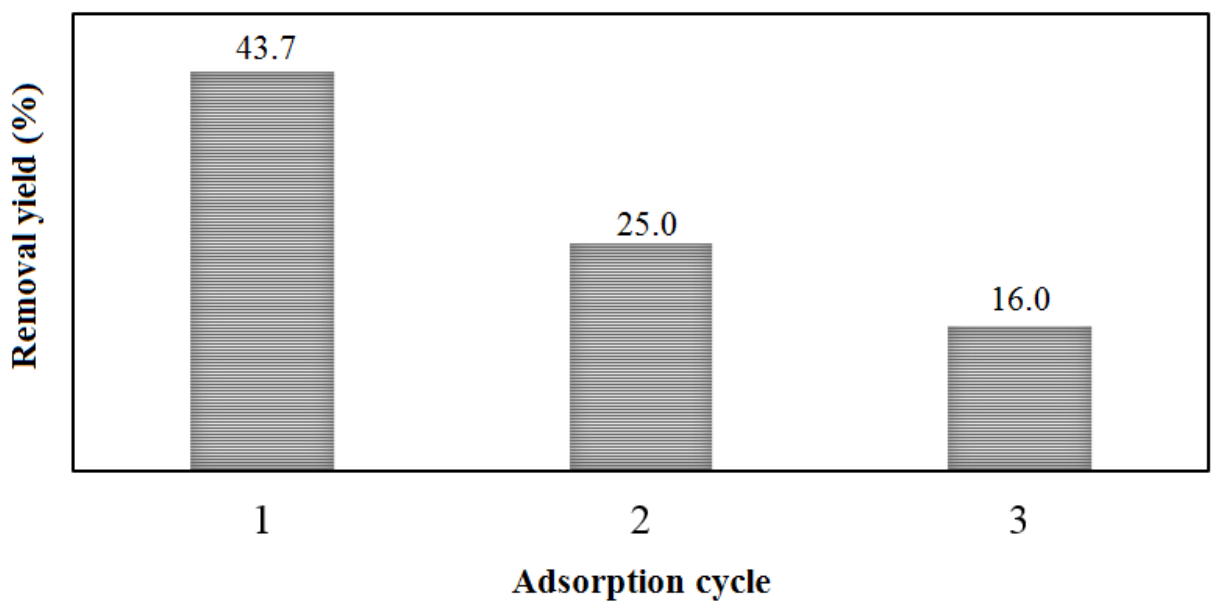

Figure 6. Desorption-adsorption experiments for $\mathrm{Cr}(\mathrm{VI})$ ions uptake using OP biosorbent in batch system.

\section{Conclusions}

This work was focused on studying adsorption process of $\mathrm{Cr}(\mathrm{VI})$ using orange peel biomass and evaluating the effect of biomass modification with $\mathrm{CaCl}_{2}$ on removal yield. The FT-IR analysis performed to OP and $\mathrm{OP}-\mathrm{CaCl}_{2}$ showed the presence of hydroxyl and carboxyl groups on biosorbent surface. The highest removal yield on adsorption batch experiments was achieved under operating conditions of $\mathrm{pH}=2$ and particle size $=0.355$ $\mathrm{mm}$. The kinetic and isotherm models that best fitted experimental data were those purposed by Elovich and Freundlich, respectively. The isotherm parameters suggested a chemisorptions process in multi-layers and heterogeneous surface of biosorbent. In addition, Cr (VI) adsorption capacity did not exhibit improvement with modification of orange peels biomass with $\mathrm{CaCl}_{2}$. The adsorption dynamic process was studied on packed-bed columns and it was found rapid biomass saturation with breakthrough time of $120 \mathrm{~min}$ and adsorption capacity of $10.28 \mathrm{mg} / \mathrm{g}$. The results of removal Cr (VI) on continuous system obeyed Yoon-Nelson and Dose-response models. Desorption of biomass revealed that OP biosorbent can be used repeatedly in removal process despite the reduction of its capacity. Hence, biosorbent from orange peels can be successfully used on $\mathrm{Cr}$ (VI) uptake.

\section{Acknowledgments}

The authors are thankful to Colombian Administrative Department of Science, Technology and Innovation COLCIENCIAS for their support to the development of this study through the Young Researchers Program, and to University of Cartagena for providing the materials and equipment necessary for successfully conclude this research.

\section{References}

1. Kaur A, Sharma S. Removal of heavy metals from waste water by using various adsorbents: A review, Indian Journal of Science and Technology. 2017; 10(34):1-14. crossref, crossref, crossref, crossref, crossref, crossref, crossref, crossref, crossref, crossref, crossref, crossref.

2. Tseng C, Lei C, Chen Y. Evaluating the health costs of oral hexavalent chromium exposure from water pollution: A case study in Taiwan, Journal of Cleaner Production. 2018;172:819-26. crossref.

3. Goyal K, Arora S. Equilibrium and kinetic studies of adsorption of lead using low cost adsorbents, Indian Journal of Science and Technology. 2016; 9(44):1-6. crossref.

4. Omorogie M, Babalola J, Unuabonah E, Song W, Gong J. Efficient chromium abstraction from aqueous solution using a low-cost biosorbent: Naucleadiderrichii seed biomass waste, Journal of Saudi Chemical Society. 2016; 20(1):49-57. crossref.

5. Dhanakumar S, Solaraj G, Mohanraj R, Pattabhi S. Removal of $\mathrm{Cr}$ (VI) from aqueous solution by adsorption using cooked tea dust, Indian Journal of Science and Technology. 2007; 1(2):1-6.

6. Pradhan D, Sukla L, Sawyer M, Rahman P. Recent bioreduction of hexavalent chromium in wastewater treatment: A review, Journal of Industrial and Engineering Chemistry. 2017; 55:1-20. crossref.

7. Mane V, Suryawanshi M, Kumbhar G, Sahu P, Gajbhiye P. Adsorption for the removal of chromium using natural 
adsorbents, International Research Journal of Engineering and Technology. 2016; 3(8):1951-55.

8. Ghazy S, El-Asmy A, EL-Nokrashy A. Separation of chromium (III) and chromium(VI) from environmental water samples using eggshell sorbent, Indian Journal of Science and Technology. 2008; 1(6):1-7.

9. Basu M, Guha A, Ray L. Adsorption of lead on cucumber peel, Journal of Cleaner Production. 2017; 151:603-15. crossref.

10. Rao H, King P, Kumar YP. Experimental investigation and statistical modeling of the cadmium adsorption in aqueous solution using activated carbon from waste rubber tire, Indian Journal of Science and Technology. 2016; 9(45):1-13.

11. Hashemian S, Salari K, Yazdi ZA. Preparation of activated carbon from agricultural wastes (almond shell and orange peel) for adsorption of 2-pic from aqueous solution, Journal of Industrial and Engineering Chemistry. 2014; 20(4):1892-900. crossref.

12. Pizarro C, Escárcega M, Gutierrez M, Ramos A, Gutierrez $\mathrm{D}$, Venegas K. Use of biomass-derived from pecan nut husks (Caryaillinoinensis) for chromium removal from aqueous solutions, column modeling and adsorption kinetics studies, Revista Mexicana de Ingeniería Química. 2017; 16(3):939-53.

13. Martín-Lara M, De Hoces M, Gálvez A, Mu-oz A, Miranda M. Assessment of the removal mechanism of hexavalent chromium from aqueous solutions by olive stone, Water Science and Technology. 2016; 73(11):2680-88. crossref. PMid: 27232404.

14. Reddy T, Chauhan S, Chakraborty S. Adsorption isotherm and kinetics analysis of hexavalent chromium and mercury on mustard oil cake, Environmental Engineering Research. 2016; 22(1):95-107. crossref.

15. Rangabhashiyam S, Suganya E, Selvaraju N. Packed bed column investigation on hexavalent chromium adsorption using activated carbon prepared from swietenia mahogani fruit shells, Desalination and Water Treatment. 2016; 57:13048-55. crossref.

16. Wu Y, Fan Y, Zhang M. Functionalized agricultural biomass as a low-cost adsorbent: utilization of rice straw incorporated with amine groups for the adsorption of $\mathrm{Cr}$ (VI) and Ni (II) from single and binary systems, Biochemical Engineering Journal. 2016;105:27-35. crossref.

17. Mohammad M, Yakub L, Yaakob Z, Asim N, Sopian K. Adsorption isotherm of chromium (Vi) into zncl2 impregnated activated carbon derived by jatropha curcas seed hull, Materials Science and Engineering. 2017; 293:12013. crossref.

18. Emilia M, Vanesa G, Ricardo P, Lea A. Activated carbon developed from orange peels: Batch and dynamic competitive adsorption of basic dyes, Industrial Crops and Products. 2014; 64:437-45.

19. Hannachi Y, Shapovalov N, Hannachi A. Adsorption of nickel from aqueous solution by the use of low-cost adsorbents, Korean Journal of Chemical Engineering. 2010; 27(1):152-58. crossref.

20. Villanueva C, Tapia H. Bioadsorción de Cu (II) porbiomasas que contienenpectina, Revista Peruana de Química e Ingeniería Química. 2005; 8(1):11-15.

21. Nacke H, Goncalves A, Coelho G. Removal of Cd (II) from water using the waste of jatropha fruit (Jatropha curcas L.), Applied Water Science. 2017; 7(6):3207-22. crossref.

22. Nacke H, Gonçalves A, Coelho G. Adsorption of Cu (II) and Zn (II) from Water by Jatropha curcas L. as Biosorbent, Open Chemistry. 2016; 14(1):103-17. crossref.

23. Resende J, Nunes D, Reis E. Cinética de adsorção de Cr (VI) de soluçõesaquosasusandosementes de acerola, Scientia Plena. 2014; 10(10):1-10.

24. Gupta A, Balomajumder C. Simultaneous removal of $\mathrm{Cr}(\mathrm{VI})$ and phenol from binary solution using Bacillus sp. immobilized onto tea waste biomass, Journal of Water Process Engineering. 2015; 6:1-10. crossref.

25. Chauhan D, Sankararamakrishnan N. Modeling and evaluation on removal of hexavalent chromium from aqueous systems using fixed bed column, Journal of Hazardous Materials. 2010; 185(1):55-62. crossref. PMid: 20943316.

26. Sakulthaew C, Chokejaroenrat C, Poapolathep A. Hexavalent chromium adsorption from aqueous solution using carbonnano-onions (CNOs), Chemosphere. 2017;184: 1168-74. crossref. PMid: 28672698.

27. Ali R, Hamad H, Hussein M, Malash G. Potential of using green adsorbent of heavy metal removal from aqueous solutions: Adsorption kinetics, isotherm, thermodynamic, mechanism and economic analysis, Ecological Engineering. 2016; 91:317-32. crossref.

28. Han Y, Cao X, Ouyan X, Sohi S, Chen J. Adsorption kinetics of magnetic biochar derived from peanut hull on removal of Cr (VI) from aqueous solution: Effects of production conditions and particle size, Chemosphere. 2016; 145:336-41. crossref. PMid: 26692510.

29. Nadeem R, Manzoor Q, Iqbal M, Nisar J. Biosorption of $\mathrm{Pb}(\mathrm{II})$ onto immobilized and native Mangiferaindica waste biomass, Journal of Industrial and Engineering Chemistry. 2016; 35:184-95. crossref.

30. Tejada-Tovar, Herrera A, Zarur J. Remoción de plomo por biomasas re siduales de cáscara de naranja (Citrus sinensis) y zuro de maíz (Zea Mays), Revista U.D.C.A Actualidad and Divulgación Científica. 2016; 19(1):169-78.

31. Soniya M, Krishnakumar G. Biosorption of Heavy Metals from Aqueous solution using Mangrove fern Acrostichumaureum L. leaf Biomass as a Sorbent, 
International Research Journal of Environment Science. 2015; 4(11):25-31.

32. Sepehr M, Amrane A, Karimaian K, Zarrabi M, Ghaffari H. Potential of waste pumice and surface modified pumice for hexavalent chromium removal: Characterization, equilibrium, thermodynamic and kinetic study, Journal of Taiwan Institute of Chemical Engineering. 2014; 45(2):635-47. crossref.

33. Singha B, Das S. Biosorption of Cr (VI) ions from aqueous solutions: kinetics, equilibrium, thermodynamics and desorption studies, Colloids and surfaces B: Biointerfaces. 2011; 84(1):221-32. crossref. PMid: 21282045.

34. Foo K, Hameed B. Preparation, characterization and evaluation of adsorptive properties of orange peel based activated carbon via microwave induced $\mathrm{K} 2 \mathrm{CO} 3$ activation, Bioresource Technology. 2011;102(20):9814-17. crossref, crossref. PMid: 21871796.

35. Pérez A, Meseguer V, Saenz O, Llorens M. Biosorption of chromium (III) by orange (Citrus cinensis) waste: Batch and continuous studies, Chemical Engineering Journal. 2009; 155(1/2):199-206. crossref. 